\title{
Aqua Dredger River Cleaning Machine
}

\author{
Kaushal Patwardhan ${ }^{1}$, Shivraj Hagawane ${ }^{2}$ and Ashish Kalokhe ${ }^{3}$ \\ ${ }^{1}$ Department of Mechanical Engineering, \\ Nutan Maharashtra Institute of Engineering and Technology, \\ Talegaon, Maharashtra, India
}

\begin{abstract}
This project focuses on design and fabrication of the river waste cleaning machine. The work has done looking at the current situation of our national rivers which are dump with core liters of sewage and loaded with pollutants, toxic materials, debris etc. The government of India has taken charge to clean rivers and invest huge capital in many river cleaning projects like "Namami Ganga", "Narmada Bachao" and many major and medium projects in various cities like Ahmadabad, Varanasi etc. By taking this into consideration, this machine has designed to clean river water surface.

Nowadays almost all the manufacturing process is being atomized in order to deliver the products at a faster rate but also at higher cost. Automation plays an important role in when it comes to smart work. In this project we have fabricated the remote operated river cleaning machine. The main aim of the project is to reduce the man power and time consumed for cleaning the river. In this project we have automated the operation of river cleaning with help of a motor and chain drive arrangement. Also a special purpose harvesting cutter is commissioned on a previous constructed model by other group of engineers. These project also emphasizes of the economical approach for implementation in urban areas.
\end{abstract}

Keywords: Aqua Dredger. Harvesting Cutter. Pick ups . Cutting Edge . Twister Edge .

\section{INTRODUCTION}

Rivers are important part of human lives. But unfortunately, only few are aware of its importance. The proof: tons of trash in our rivers and creeks, making it look and smell like a dumpsite. The garbage in rivers is more than just an eyesore because it can possibly contaminate our drinking water and threaten nature, our lives, and that of our loved ones. Even a piece of litter thrown on the street may contribute to the piling garbage in our rivers and creeks. Rivers remain an important source of drinking water for many towns and cities. The water is purified first before it reaches to our tap. However, if our rivers remain polluted, the water can't be purified to the extent that it won't be suitable for human consumption anymore. It is crucial to look after our river systems and protect them from pollution to we want them to keep on flowing to our taps. Rivers provide habitat to a wide range of animal and plant species. However, these species are already critically endangered due to the rapid deterioration of our rivers. These endemic species, can only be found in the Philippines, may be saved if we clean up our rivers. Clean, healthy rivers reduce human health risk and improved quality of life. Less trash increase recreational activities along rivers - clean and safe walk and run trails for the community. As recreational activities increases, tourists will be attracted. This affects both the economy and well- being of the community. We could draw inspiration from Iloilo City. How they successfully revived their main river and built a beautiful Esplanade, the first of its kind in our country, with their key guiding principles of "unity, strategic planning, and political will". It's all up to us to make it happen. As human and industrial waste and garbage add up to the river pollution, each of us can do small things to help clean up our river and that adds up to the pollution solution

\section{LITERATURE REVIEW}

Design, Fabrication and Analysis of Composite Marine Propeller, Dr, P Ravinder Reddy, CBIT, Hyderabad From this paper, a composite marine propeller is designed and modeled from three composite materials. The model is evaluated for its open water characteristics and cavitation performance numerically using hydro-elastic model. To validate the results, composite propeller is fabricated using open mold technique and is tested in cavitation tunnel available at NSTL vizag. From the results it is concluded that, the hydro-elastic model used for analysis of composite propeller is in close agreement with experimental results. The stacking sequence which contributed to the optimum performance is selected from the choice of stacking sequences. The results of the same are presented in this paper.

Design of continuous loading vertical chain conveyor, Aditya Kulkarni, Tanmay Kulkarni,PES Modern college of Engineering, Pune, Maharshtra,

A conveyor system is a common piece of mechanical Handling equipment that moves materials from one location to another. The main purpose of this project is to safely lift the load at the rate of $6 \mathrm{~m} / \mathrm{min}$. This paper consist of, selection, the design of basic mechanical elements. This system is able to overcome the drawbacks of inclined belt conveyor, achieves desired height and occupies less floor space as the material is transformed in vertically upward direction. This Chain Conveyor utilizes a continuous chain arrangement, carrying a series of the single pallet for lifting the load. The chain arrangement is driven by a motor, and the material suspended on the pallets is conveyed to the next floor. 
Design and Analysis of Composite Marine Propeller using ANSYS WORK BENCH, S. Abdul Mutalib, S. Suresh, S.Jaya Kishore, Department of Mechanical Engineering, Siddarth institute of Engineering and Technology, Puttur, A.P, India. Present work progress a methodology to design a propeller with isotropic material such as aluminum and composite materials to analyze its strength and deformation using ANSYS WORK BENCH software. To compare the effectiveness of aluminum metal and composite material such as CFRP and GFRP, static analysis and dynamic analysis are performed on these different materials. The solid model of marine propeller is developed using Solid works. This works approaches the substantial improvements in metal propellers. The stress, strain and the total deformation were found out both the aluminum and the composite marine propeller using ANSYS. The stresses obtained are well within the limit of elastic property of the materials. The results are compared with aluminum and Composite marine propeller for the maximum stress and maximum deformation.

\section{Design and fabrication of River Cleaning Machine, Saif Ali Sayyad, Adarsh Dorlikar, Sneha Ratanparkhi, Tanvi Bhagat, RCERT, Chandrapur, India MH.}

This project focuses on design and fabrication of the river waste cleaning machine. "River cleaning machine" a machine which involves the removing the waste debris from water surface and safely dispose from the water body. The work has done looking at the current situation of our national rivers which are dump with core liters of sewage and loaded with pollutants, toxic materials, debris etc. Due to increase in water pollution in the form to waste debris; it is hampering the life of aquatic animal and make their life in danger. A machine will lift the waste surface debris from the water bodies, this will ultimately result in reduction of water pollution and lastly the aquatic animal's death to these problems will be reduced. The main aim of the project is to reduce the man power, time consumption for cleaning the river. In this project we have store the energy in the battery and used this energy for river cleaning with the help of a motor and chain drive arrangement.

\section{AQUA DREDGER AND LIST OF PROPOSED PARTS}

River cleaning machine a machine which involves the removing the waste debris from water surface and safely dispose from the water body. The work has done looking at the current situation of our national rivers which are dump with core liters of sewage and loaded with pollutants, toxic materials, debris etc. Our project is a replica or prototype of the actual model with a new system incorporated in it for greater efficiency.

The motive of the project is to automate the sewage cleaning process in drainage, to reduce the spreading of diseases to human. The black water cleaning process helps to prevent pest infestations by reducing the residues that can attract and support pests. It also improves the shelf life and sensory quality of food products. In the proposed system, the machine is operated with remote control to clean the sewage. Hence, this system avoids the impacts from the sewage waste and its harmful gases. This helps to prevent the mosquito generation from the wastage.

Initial design and part modeling is based on a research paper of prosed model with reference paper number [5]

We have introduced a Cutter blade mounted on rotating shaft to force out river waste effectively without any leftover unlike other models. This blade enables the vessel to catch as well as cut the waste in water body by its special design.

\begin{tabular}{|c|c|c|c|}
\hline $\begin{array}{c}\text { Part } \\
\text { No }\end{array}$ & Parts & $\begin{array}{l}\text { Part } \\
\text { No. }\end{array}$ & Parts \\
\hline 3.1 & Cutter and Cutter Shaft & 3.4 & Conveyor shaft and system \\
\hline 3.2 & Chain [Ref 05] & 3.5 & Base Frame [Ref 05] \\
\hline 3.3 & Propeller [Ref ] & 3.6 & Float [Ref 05] \\
\hline
\end{tabular}




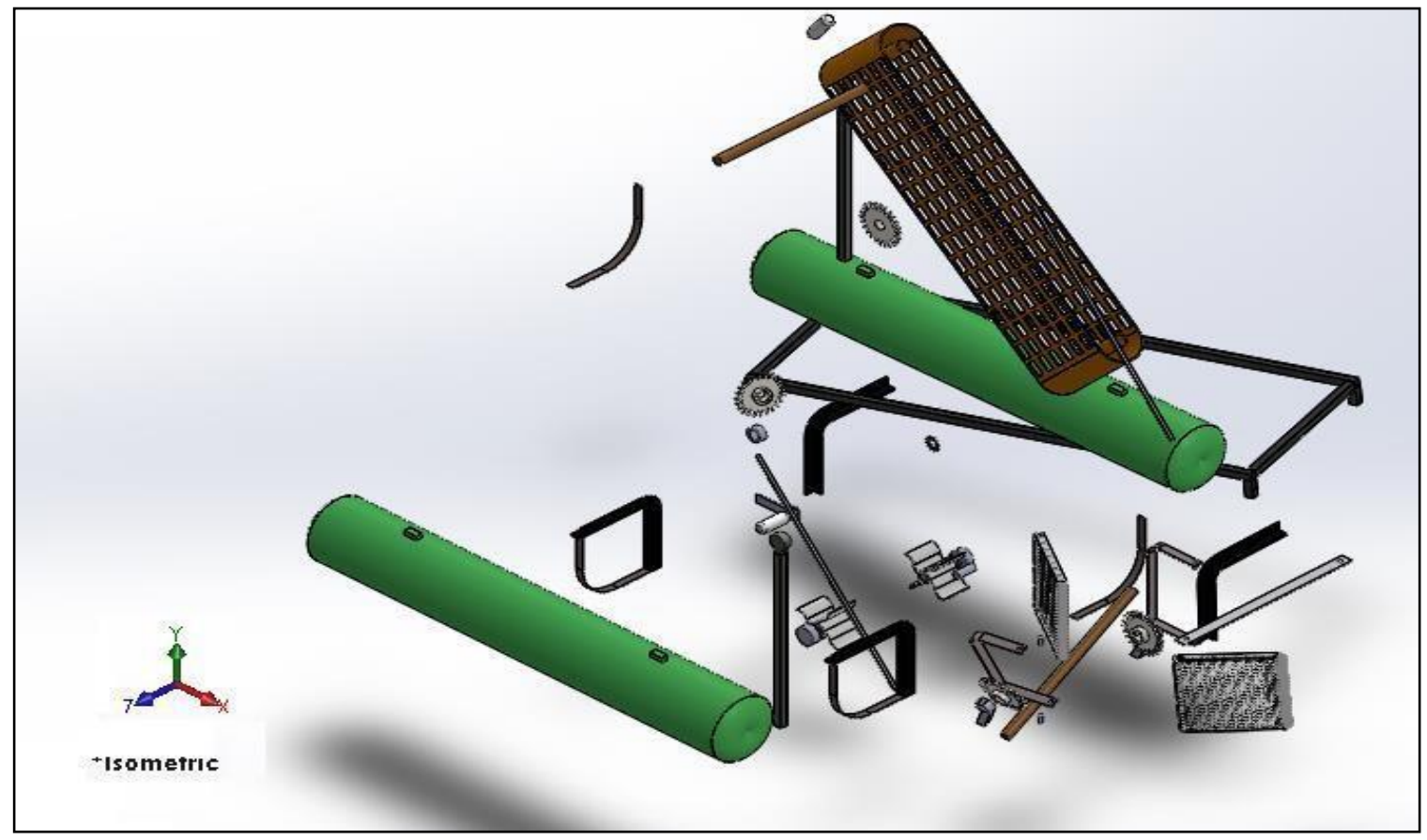

Fig Exploded View Past Model

Cutter is made up of case hardened zinc coated steel. This cutter has 6 blades and 6 pickups to harvest hyacinth and collect it in conveyor. Hyacinth is generally 6 meters deep and $0.3 \mathrm{~m}$ wide. Thus the construction of cutter is determined considering the depth it needs to work on. Also material is consideration is done by working of it in salty water and harsh conditions. In process of determining the parameters of cutting wheel, blades and shafts following points are considered. Suitable material for cutter to withstand forces of water density and Hyacinth used is 15N20 Case Hardened Steel (Reference ASMS).

$\begin{array}{lclc}\text { Material } & \begin{array}{c}\text { Percentage } \\ \text { Concentration } \\ \text { Carbon }\end{array} & \text { Material } & \begin{array}{c}\text { Percentage } \\ \text { concentration }\end{array} \\ \text { Manganese } & 0.75 \% & \text { Phosphorous } & 0.10 \% \\ \text { Nickel } & 0.40 \% & \text { Silicon } & 0.25 \% \\ & 2 \% & \text { Ferrum (Iron) } & 96.5 \%\end{array}$

Considering the depth of waste and submerged cutter part the distance from Cutting edge to Axis is $395 \mathrm{~mm}$

According to IFAS Center for Aquatic and Invasive Plants the normal mass of hyacinth maximizes to $2.5 \mathrm{Kg}$ across $300 \mathrm{~mm}$ Thus in $840 \mathrm{~mm}$ mass $=7 \mathrm{Kg}$ Force $=$ mass $\mathrm{x}$ Acceleration

$=7 \times 9.81$

$=68.67 \mathrm{~N}$ on each submerged blade Thus for 3 blades

Force $=68.67 \times 3=206.01 \mathrm{~N} \approx 250 \mathrm{~N}$

Torque $=$ Force $\mathrm{x}$ Radius

$=250 \times 396$

$=99 \mathrm{Nm} \approx 100 \mathrm{Nm}$

Bending Moment of shaft is caused existing weight of cutter and pick up edges and weight of shaft itself. Material to be used for shaft is Case Hardened EN24 Steel

Density $=7480 \mathrm{Kg} / \mathrm{m} 3$

Thus, Weight Density $=733880$ N/m3 
Volume of Shaft $=\pi \mathrm{r}^{\wedge} 2 * \mathrm{~L}$

$=3.14 \times(0.05) 2 \times 0.82$

$=0.006437 \mathrm{~m} 3$

Force UDL $=$ Weight Density $\times$ Volume

$=76910 \times 0.006437$

$=495.06 \mathrm{~N}$ over Length

Considering the initial assumed diameter of shaft to be $100 \mathrm{~mm}$ diameter Force exerted by Blades $=60.2824 \mathrm{~N}$ Force exerted by Pickups $=55.132 \mathrm{~N}$ Calculated by Standard Consideration Point Load at Center $=495.06 \mathrm{x} 1$ $=495.06 \mathrm{~N}$

Thus Calculating Maximum Bending Moment

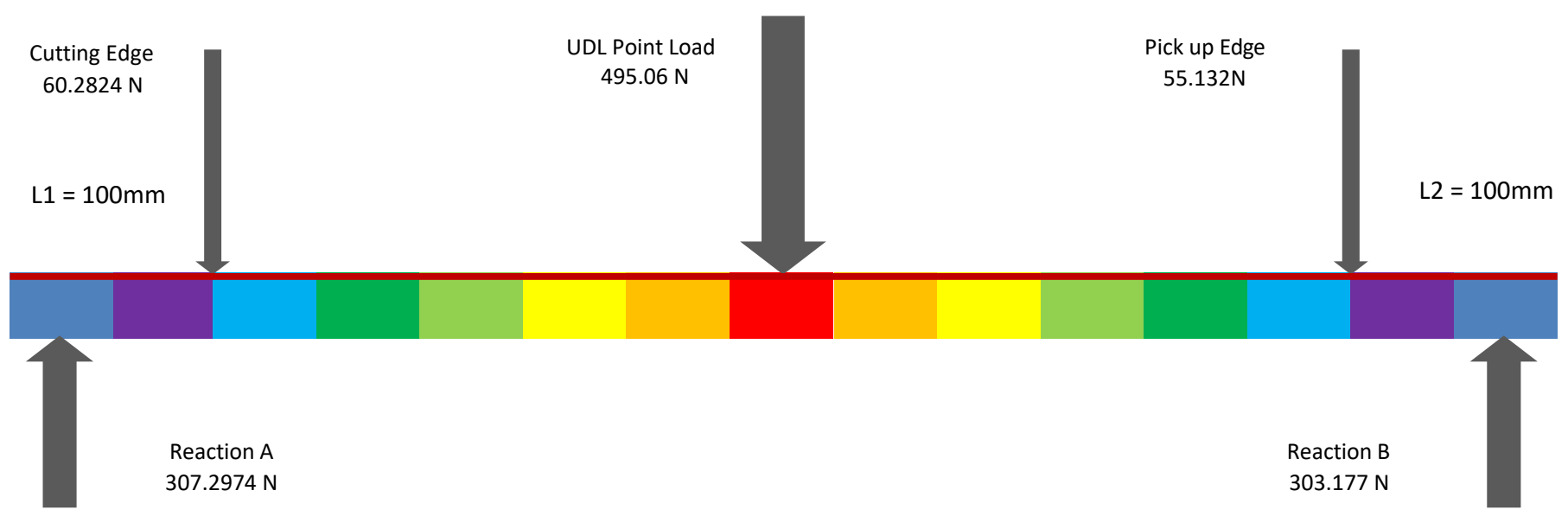

Length $=1000 \mathrm{~mm}$

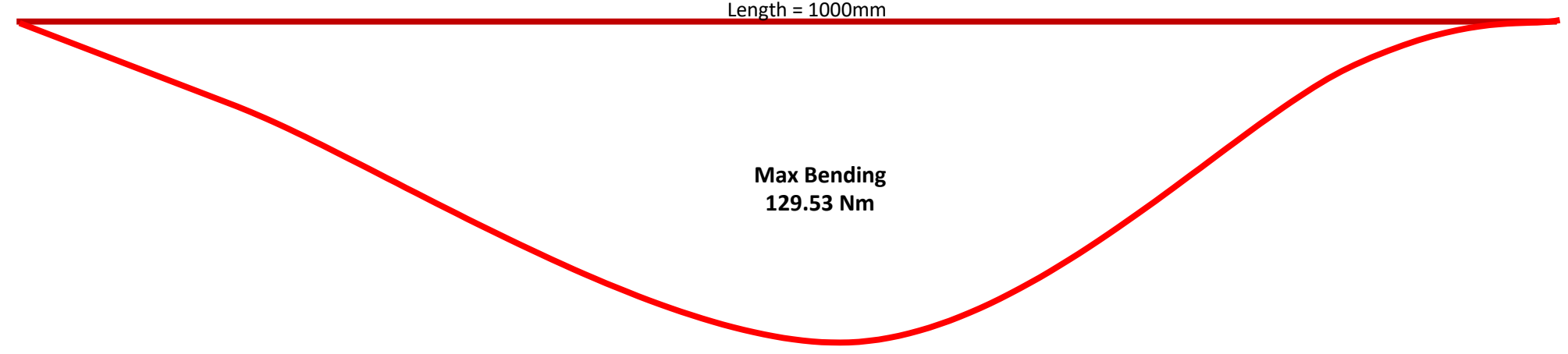

Fig 3.5 Max Bending Moment

After force calculation maximum bending moment was found out to be $\mathrm{M}=129.53 \mathrm{Nm}$

Selected shaft is subjected to shocks and fatigue stress Thus

Respective Shock factor $=\mathrm{KB}=1.7$

Respective Fatigue Factor=KT=1.3 With

Reference to Design data table

Calculation Equivalent Torsion and Bending Cutter Shaft Diameter by Strength Method

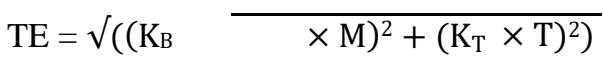

$\left.\overline{=\sqrt{ }\left((1.7 \times 129.53)^{2}+(1.3 \times 100)^{2}\right.}\right)$

$$
\begin{aligned}
& \mathrm{TE}=\pi \times \mathrm{d}^{3} \times \tau \quad-\quad \text { per } \\
& 16 \\
& 225.71=\pi \times \mathrm{d}^{3} \times 62.1 \times 10^{9} \\
& \mathrm{D}=0.0586 \mathrm{~m} \approx 60 \mathrm{~mm}
\end{aligned}
$$$$
\mathrm{TE}=225.71 \mathrm{Nm}
$$ 
- Total Diameter of cutter : $790 \mathrm{~mm}$

- Cutting Edge : $820 \mathrm{~mm}$

- Total Length : $1280 \mathrm{~mm}$

- $\quad$ Pickup Edge : $630 \mathrm{~mm}$

- $\quad$ Shaft Diameter : $60 \mathrm{~mm}$

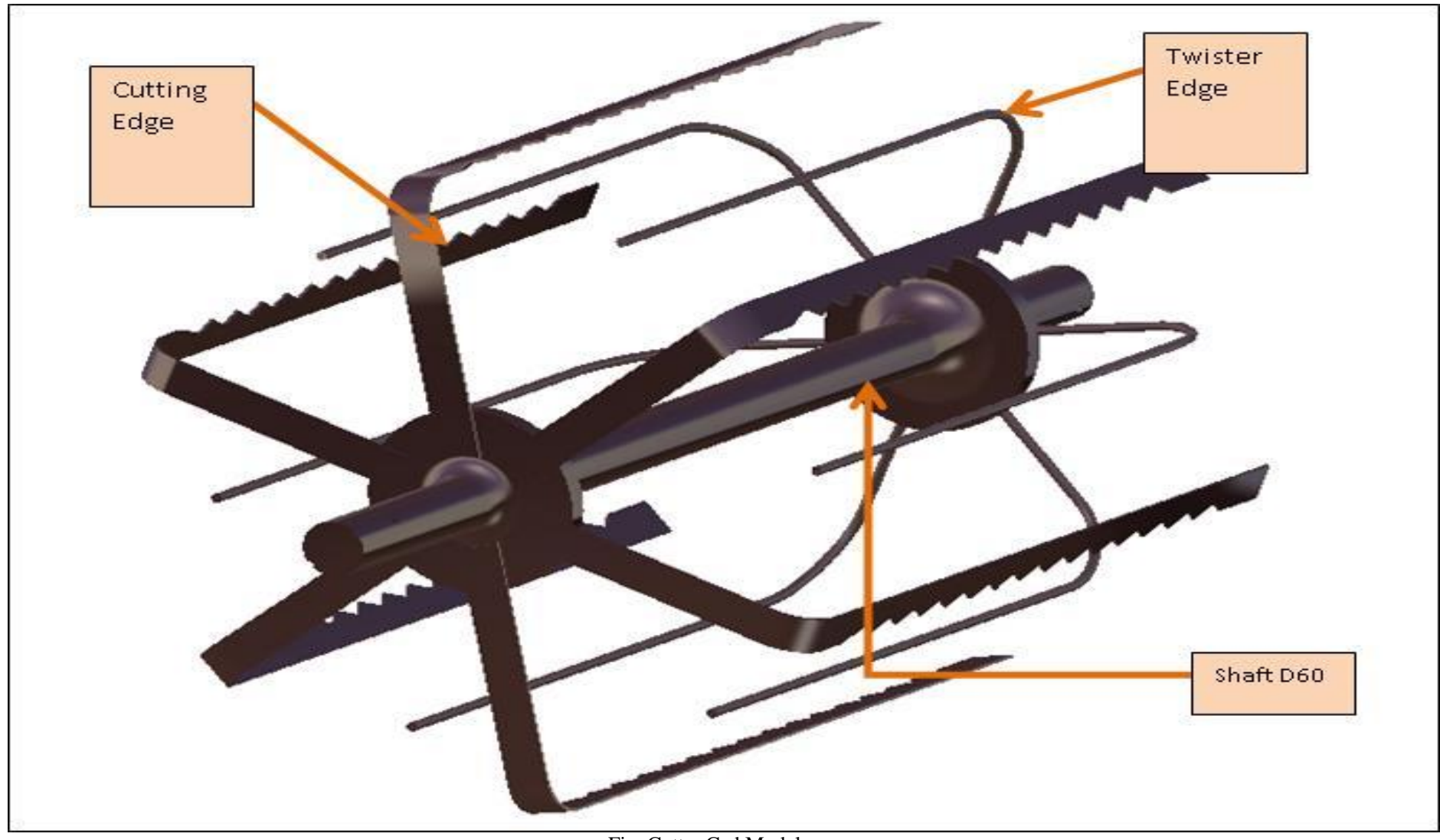

Fig. Cutter Cad Model

\section{A: Static Structural}

Equivalent Stress

Type: Equivalent (von-Mises) Stress

Unit: MPa

Time: 1

$12 / 12 / 20197: 19 \mathrm{PM}$

\begin{tabular}{|l}
266.53 Max \\
236.92 \\
207.3 \\
177.69 \\
148.07 \\
118.46 \\
88.845 \\
59.23 \\
29.615 \\
\hline $1.4197 \mathrm{e}-10$ Min
\end{tabular}

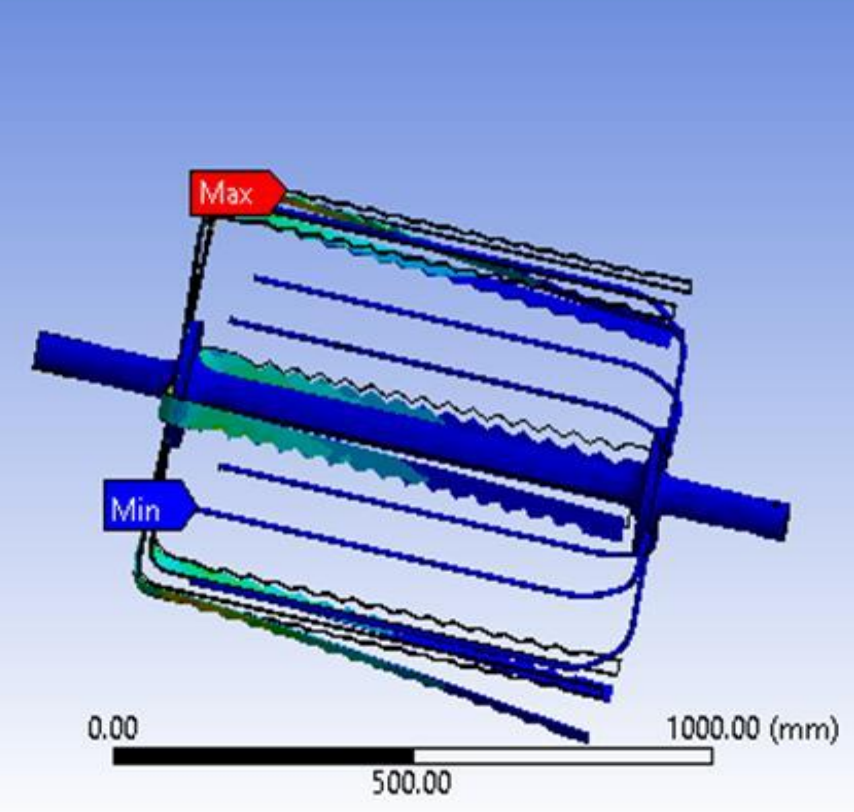

Fig. Stress Analysis of Cutter 
Following the research, the shaft designed is powered by chain drive. Chain drive is a way of transmitting mechanical power from one place to another. It is often used to convey power to the wheels of a vehicle, particularly bicycles and motorcycles. It is also used in a wide variety of machines besides vehicles

Most often, the power is conveyed by a roller chain, known as the drive chain or transmission chain, passing over a sprocket gear, with the teeth of the gear meshing with the holes in the links of the chain. The gear is turned, and this pulls the chain putting mechanical force into the system.

Chain Driven Live Roller (CDLR) conveyor is made up of a series of rollers aligned inside two side frames. The rollers are then connected via sprockets and chain to a drive motor mounted to the side of the conveyor. These pulleys, being made of steel, are able to convey far heavier products compared to plastic based conveyors like table tops and modular belts. The down side of such a conveyor, however, is the relatively large gaps between the rollers limiting the size of the products that can be effectively conveyed.

\section{Design of Chain Drive Used}

1) Determine the velocity ratio of the chain drive Velocity ratio $=$ N1/N2

So,

$\mathrm{N} 1 / \mathrm{N} 2=\mathrm{T} 2 / \mathrm{T} 1$

Velocity ratio $=0.4$

2)

Select the minimum number of teeth on the smallest sprocket or pinion Minimum Number of Teeth on the Sprocket

$=18$

3)

Determine the design power by using the service factor, such that, Design power $=$ Rated power $\mathrm{x}$ Service

factor $(\mathrm{Ks})$

$=106.25 \times$ Service factor $(\mathrm{Ks})$

$=106.25 \times$ (Load factor $(\mathrm{K} 1) \times$ (Lubrication factor $(\mathrm{K} 2) \times$ Rating factor $(\mathrm{K} 3)$

$=106.25 \times(1.5 \times 1 \times 1.25)$

Design power $=0.20 \mathrm{~kW} \mathrm{K=Flow} \mathrm{ability} \mathrm{factor}$

for 260 inclination angle of chain $=2.5 * 10-4 \mathrm{~b}=$ width of chain $=380 \mathrm{~mm}$

$\mathrm{V}=$ velocity of drive $=0.0785$

$=1500 * 2.5 * 10-4(0.9 * 380-0.05) 2 * 0.0785$

$=2.8289 * 10-3 \mathrm{Kg} / \mathrm{sec}$

$=2.8289 * 10-3 * 3600$

$\mathrm{M}=10.1841 \mathrm{Kg} / \mathrm{sec}$

4) Choose the type of chain, number of strands for the design power and RPM of the sprocket Types of chain = simple roller chain $(06 \mathrm{~B})$

Power rating $($ in $\mathrm{kW})=0.25$

Speed of sprocket or pinion $(\mathrm{RPM})=305)$

Note down the parameters of the chain, such as pitch, roller diameter, minimum width of roller. ISO chain number $=06 \mathrm{~B}(35)$

Pitch $(\mathrm{mm})=9.525$, Roller diameter $(\mathrm{mm})=6.535$ Minimum width $(\mathrm{mm})=5.72$

Braking load (simple type roller chain) in $\mathrm{k} \mathrm{N}=8.9$

6)

determine the load $(\mathrm{W})$ on the chain by using the following relation, Pitch line velocity $=3.14 \mathrm{dN} / 60$

$=(3.14 \times 0.06 \times 30) / 60$

Pitch line velocity $=0.0942 \mathrm{~m} / \mathrm{s} \mathrm{W}=$ Rated power/pitch line velocity $\mathrm{W}=0.25 /$ pitch line velocity

$\mathrm{W}=0.25 / 0.0942$

$\mathrm{W}=2.65 \mathrm{KN}$ Load on the chain $\mathrm{W}=2650 \mathrm{~N}$

7) Calculate the factor of safety by dividing the breaking load (WB) to the load on the chain (W). This value of factor should be greater than the value.

Factor of safety $=(\mathrm{WB} / \mathrm{W})$

$=8.9 / 2.65$

Factor of safety $=3.358$ 
A propeller is a device with a rotating hub and radiating blades that are set at a pitch to form a helical spiral, that when rotated performs an action which is similar to Archimedes' screw. It transforms rotational power into linear thrust by acting upon a working fluid such as water or air. The rotational motion of the blades is converted into thrust by creating a pressure difference between the two surfaces. A given mass of working fluid is accelerated in one direction and the craft moves in the opposite direction. Propeller dynamics, like those of aircraft wings, can be modeled by Bernoulli's principle and Newton's third law. Most marine propellers are screw propellers with helical blades rotating around an approximately horizontal axis or propeller shaft.

\section{Theory of Operation}

A propeller is the most common propulsion on ships, imparting momentum to a fluid which causes a force to act on the ship. The ideal efficiency of any propulsion is that of an actuator disc in an ideal fluid. This is called the Froude efficiency and is a natural limit which cannot be exceeded by any device, no matter how good it is. Any propulsion which has virtually zero slip in the water, whether this is a very large propeller or a huge drag device, approaches $100 \%$ Froude efficiency. The essence of the actuator-disc theory is that if the slip is defined as the ratio of fluid velocity increase through the disc to vehicle velocity, the Froude efficiency is equal to 1/ (slip +1$)$. Thus a lightly loaded propeller with a large swept area can have a high Froude efficiency

\section{Design and Analysis of Marine Propeller}

Design and Geometric modeling of propeller is executed by standard selection of propeller by International Journal of Engineering Technology, Management and applied science. [Ref 01]

\section{Dimensions of Turbine}

Sr No.
1
2
3
4
5
6
7

Parameter

Angle of Attack

Hub Diameter

Total Diameter

Number of blades

Hub Length

Material

Mass (Density $2780 \mathrm{Kg} / \mathrm{m}^{3}$ )
Dimension

$25^{\mathrm{O}}$

$60 \mathrm{~mm}$

$400 \mathrm{~mm}$

03

$80 \mathrm{~mm}$

2024 T6 Aluminum Alloy

$1.409 \mathrm{Kg}$

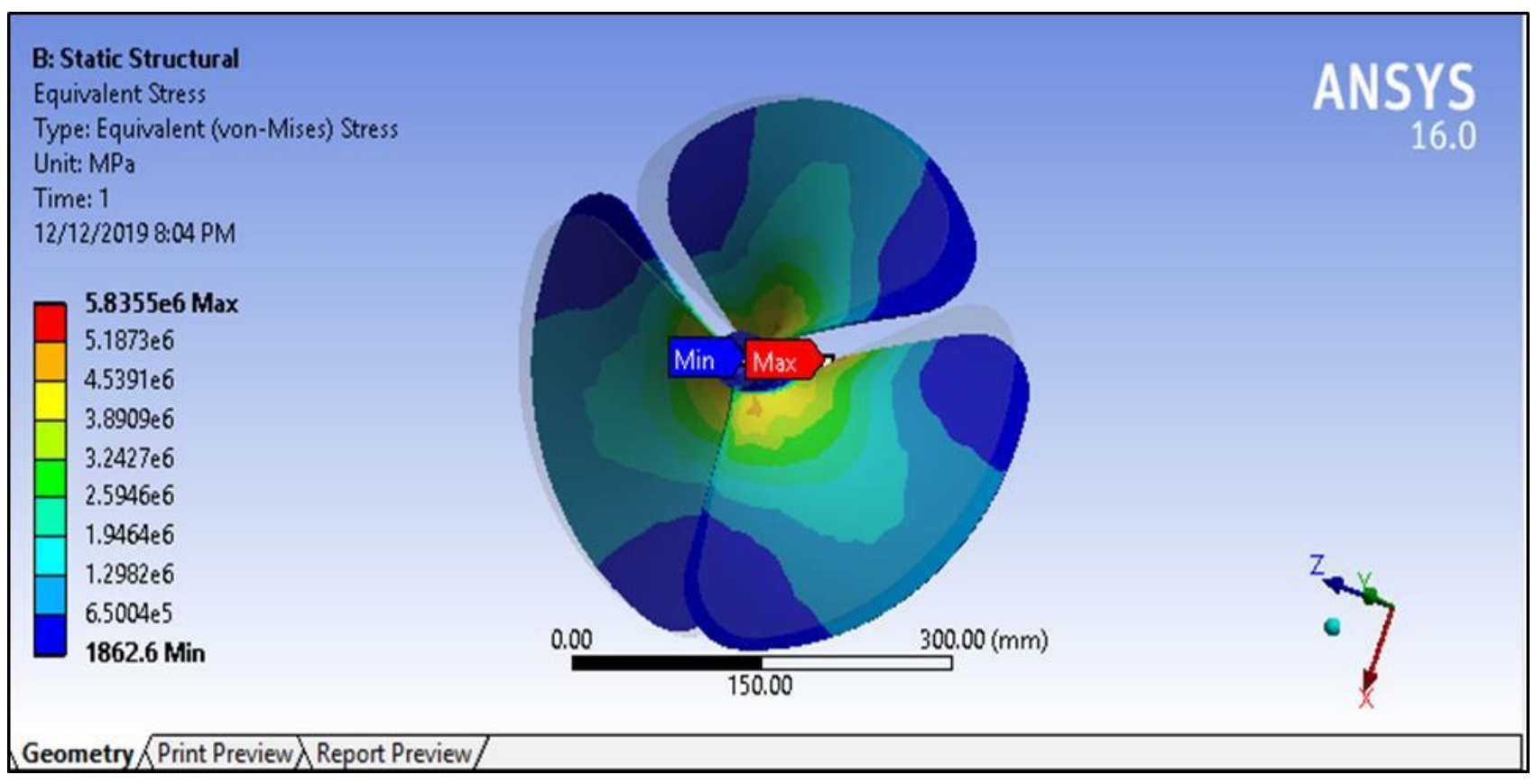

Fig. Stress Analysis of Propeller 
A conveyor system is a common piece of mechanical handling equipment that moves materials from one location to another. Conveyors are especially useful in applications involving the transportation of heavy or bulky materials. Conveyor systems allow quick and efficient transportation for a wide variety of materials, which make them very popular in the material handling and packaging industries. They also have popular consumer applications, as they are often found in supermarkets and airports, constituting the final leg of item/ bag delivery to customers. Many kinds of conveying systems are available and are used according to the various needs of different industries. There are chain conveyors (floor and overhead) as well. Chain conveyors consist of enclosed tracks, I-Beam, towline, power \& free, and hand pushed trolleys.

A conveyor system is often the lifeline to a company's ability to effectively move its product in a timely fashion. The steps that a company can take to ensure that it performs at peak capacity include regular inspections and system audits; close monitoring of motors and reducers, keeping key parts in stock, and proper training of personnel.

Conveyor Shaft

Conveyor is drawn by the grooved aluminum shaft with orderly groove which is powered by a electric motor of $2 \mathrm{HP}$. The shaft is made up of AL6061 T6 Alloy with following composition and mechanical properties considering the weight and strength

[Ref 05]

Length $=1000 \mathrm{~mm}$ Diameter $=40 \mathrm{~mm}$

Conveyor Diameter $=60 \mathrm{~mm}$

Depth of Groove $=10 \mathrm{~mm} \times 12$ Pulling Teeth

$\begin{array}{llll}\text { Property } & \text { Value of Magnitude } & \text { Property } & \text { Value of Magnitude } \\ \text { Young's Modulus } & 70 \mathrm{Gpa} & \text { Ultimate Tensile } & \text { 560Mpa } \\ \text { Hardness } & 150 \mathrm{BHN} & \text { Shear Modulus } & 26 \mathrm{Gpa} \\ \text { Fatigue Strength } & 160 \mathrm{Mpa} & \text { Poisson Ration } & 0.32 \\ \text { Content } & \mathrm{Wt} \% & \text { Content } & \mathrm{Wt} \% \\ \text { Aluminum } & 87.1-91.4 & \text { Titanium } & \text { Max } 0.20 \\ \text { Silicon } & \text { Max } 0.40 & \text { Copper } & 1.2-2.0 \\ \text { Manganese } & \text { Max } 0.30 & \text { Chromium } & 0.18-0.28 \\ \text { Magnesium } & 21 .-2.9 & \text { Zinc } & 5.1-6.1\end{array}$

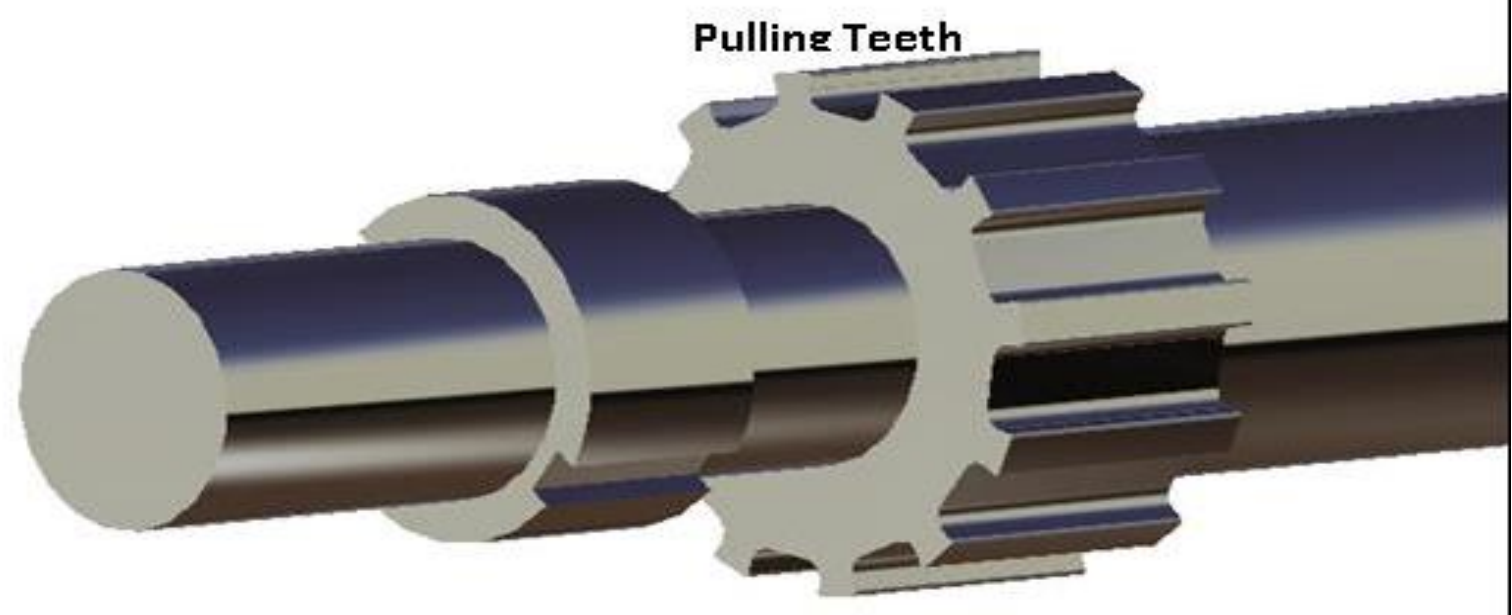

Fig. Conveyor Shaft with Pulling Teeth 


\section{CONVEYOR PICKUP ON AQUA DREDGER}

Pick up on Aqua Dredger is designed to enable water hyacinth to be picking up and drawn easily at start and dump easily at end. Pick up are made to be attached on the conveyor steel rope belt.

Vertical reciprocating conveyors (or VRC) are another type of unit handling system. Typical applications include moving unit loads between floor levels, working with multiple accumulation conveyors, and interfacing overhead conveyors line. Common material to be conveyed includes pallets, sacks, custom fixtures or product racks and more.

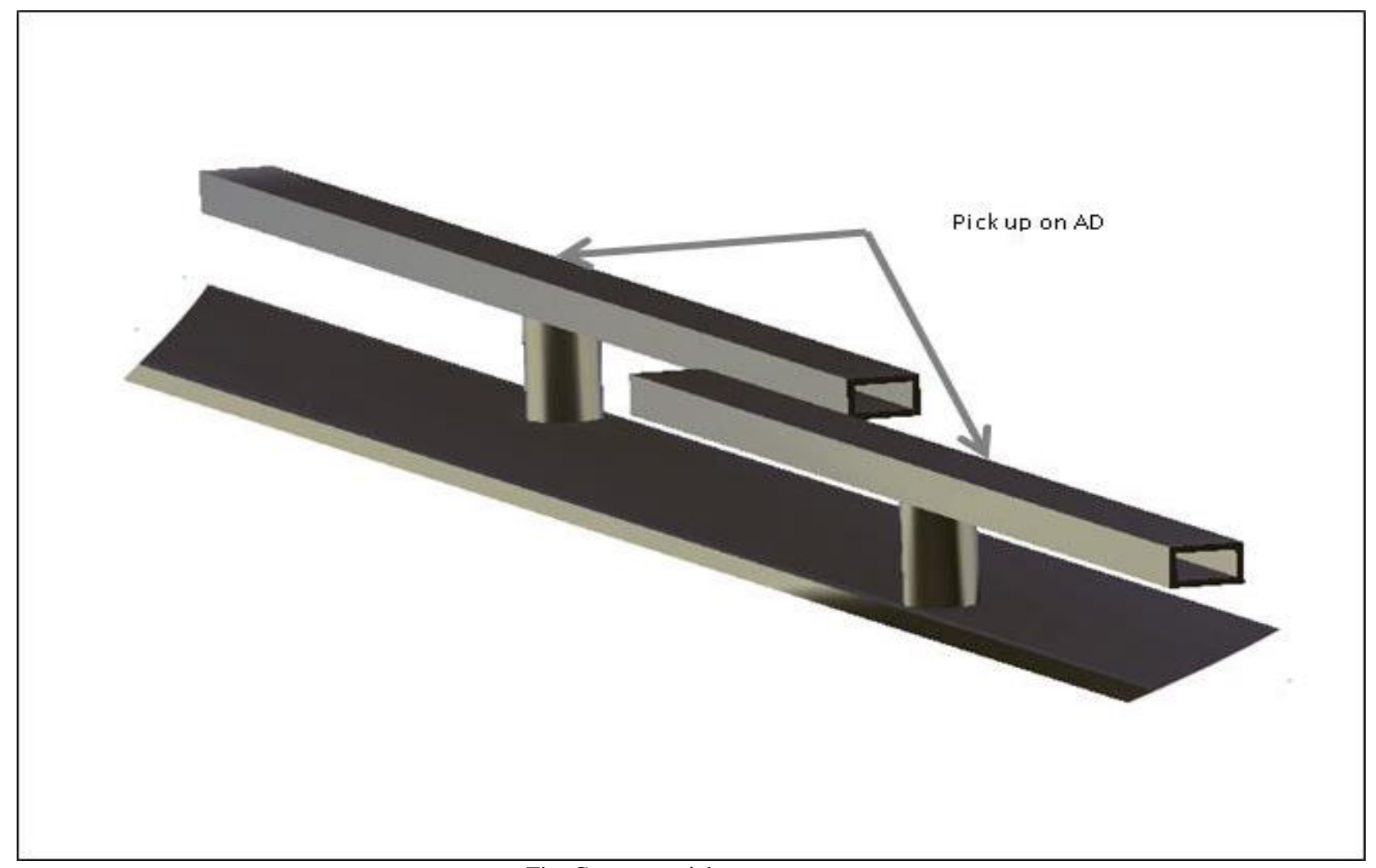

Fig. Conveyor pick up

Base frame selected is simply a structure of AISI4130 Hollow Circular pipe. This supports the entire conveyor system, Cutting Blade and shaft and storage tank of the vessel. Also it gives strength to withstand the float and maintain them into position. Propeller is connected at its end.

The frames support lengthwise members which run parallel to the keel, from the bow to the stern; these may variously be called stringers, strakes, or clamps. The clamp supports the transverse deck beams, on which the deck is laid.

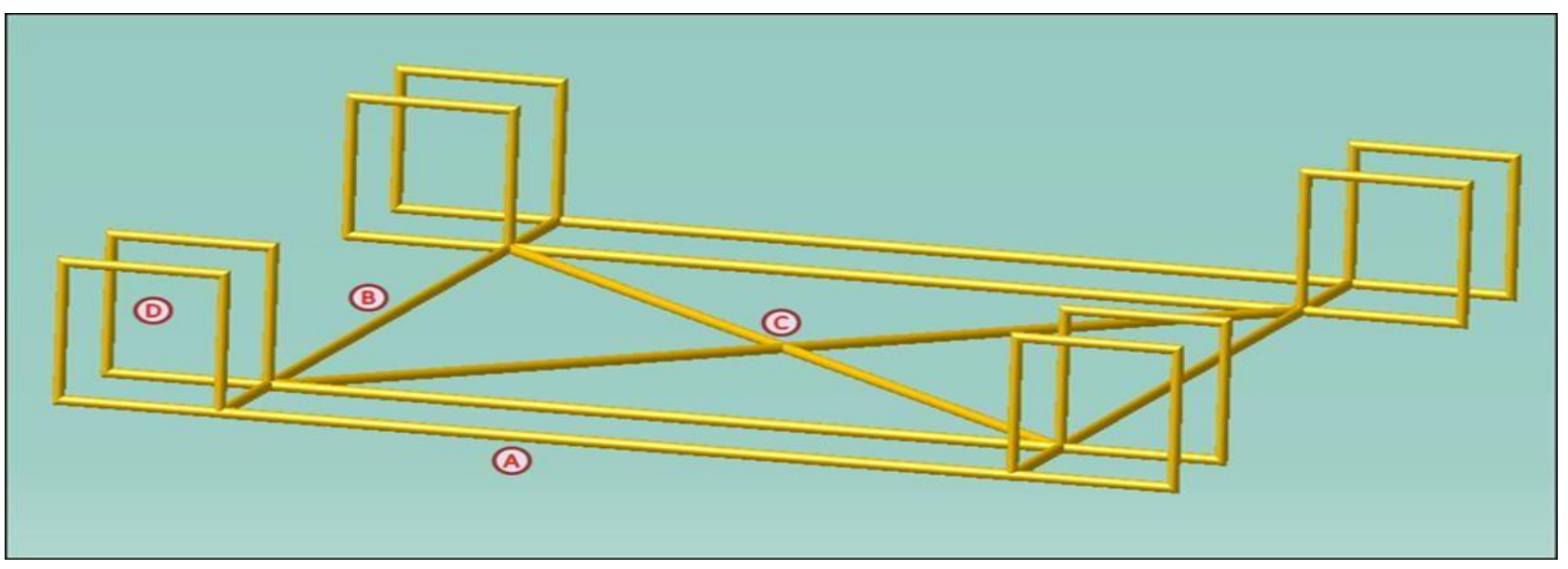




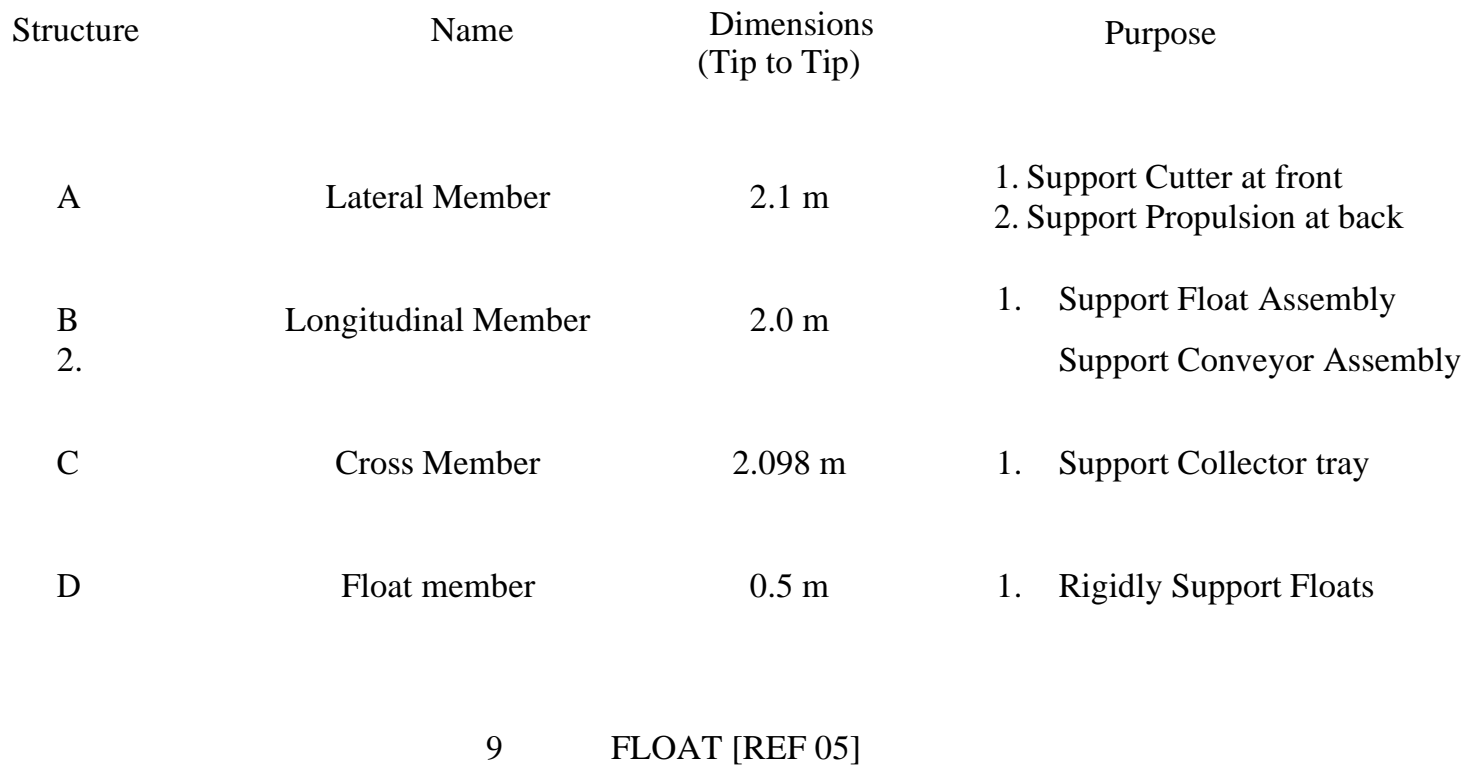

If the boat weighs less than the maximum volume of water it could ever push aside (displace), it floats. But it sinks into the water until its weight and the up thrust exactly balance. The more loads you add to a boat, the more it weighs, and the further it will have to sink for the up thrust to balance its weight.

The float dimensions are simply determined by putting into used the Archimedes principle. Its states that, 'the upward buoyant force that is exerted on a body immersed in a fluid, whether fully or partially submerged, is equal to the weight of the fluid that the body displaces'.

Thus,

Weight of Total Body is estimated to be $250 \mathrm{Kg}$ Considering FOS $=4$ and reverse principle of Archimedes

$F_{b}=\rho \times g \times V$ ... Eq (a)

$\rho=$ Density of Water $=1025 \mathrm{~kg} / \mathrm{m} 3 \mathrm{~g}=$ gravitational pull $=9.81 \mathrm{~m} / \mathrm{s} 2$

$\mathrm{V}=$ Volume of water to be displaced by float Thus, $\mathrm{Fb}=$ Estimated weight $\mathrm{x}$ FOS

$=250 \times 4=1000 \mathrm{~kg}$

Using Eq (a),

$1000=1025 \times 9.81 \times \mathrm{V} \mathrm{V}=0.4077 \mathrm{~m} .3$

Volume of float submerged in fluid $=0.4077 \mathrm{~m} 3$

Thus Considering the balance in vessel use to two floats with $0.4077 \mathrm{~m} 3$ is used Dimensions of float

Diameter of Float $=0.5 \mathrm{~m}$ Length of Float $=2.0 \mathrm{~m}$

Material selected for float is PVC Sheet with reference to [Ref 05] 


\section{ADVANTAGES AND LIMITATIONS}

Mechanical harvesters can be effective at clearing aquatic weeds but the machines are expensive and the process may need to be repeated several times in a growing season.

Small fragments of weed remain in the water and may spread to other locations thereby aiding in the dispersal of invasive species.

Some areas may be too shallow for the mechanical harvester and it may be unable to access restricted locations. Submerged tree stumps can damage the machine.

\section{FUTURE SCOPE}

In future this project can be improved to sort more categories of waste. In this system we can use advance conveyor system and conveyor material for increasing the efficiency of collection of garbage. We can use the solar panel for providing power to the boat instead of battery operation. To modify the size of boat according to its waste collecting capacity is increases. This project makes only for small lake by doing some modification in its size and capacity it can use in big lake and river like Ganga. Aqua Dredger is a pioneer

In aquatic plant and weed harvesting technology throughout the world. In coming years, Aqua Dredger's equipment can be utilized for aquatic weed harvesting and aquatic trash collection. We can design and manufacture a wide range of aquatic weed harvesting and aquatic trash removal systems including. Our equipment is designated for the removal of aquatic weeds and floating debris from water reservoirs, ports, rivers and lakes. It can be put to use over many countries.

\section{CONCLUSION}

This project is fabricated on the basis of literature and research conducted on different journal and paper relevantly available and in accordance so it can provide flexibility in operation. This innovation has turned out to be easy and less costly and has lot of room to grow more economical. This project "Aqua Dredger - River Cleaning Machine" is designed with the hope that it is very much economical and helpful to river and Pond cleaning. On the basis of it design, cost and availability it is very cheap and very useful for the society.

\section{REFERENCES}

[1] Design, Fabrication and Analysis of Composite Marine Propeller, Dr, P Ravinder Reddy, CBIT, Hyderabad

[2] Design of continuous loading vertical chain conveyor, Aditya Kulkarni, Tanmay Kulkarni,PES Modern college of Engineering, Pune, Maharshtra, Design and Analysis of Composite Marine Propeller using ANSYS WORK BENCH, S. Abdul Mutalib, S. Suresh, S.Jaya Kishore, Department of Mechanical Engineering, Siddarth institute of Engineering and Technology, Puttur, A.P, India.

[3] Design and fabrication of River Cleaning Machine, Saif Ali Sayyad, Adarsh Dorlikar, Sneha Ratanparkhi, Tanvi Bhagat, RCERT, Chandrapur, India $\mathrm{MH}$.

[4] Design and Fabrication of River Cleaning Machine, Sheikh MD Shahid MD Rafique, Dr Aakash Langde, Dept of Mechanical, Anjuman college of engineering and technology, Nagpur, Maharashtra

[5] https://www.marineinsight.com/naval-architecture/design-of-ships-bottom-structure/s 